\title{
Assessment of the Relative Level of TNF- $\alpha$ Gene Expression in RAW264.7 Cells
}

\author{
Hossein Montakhab Yeganeh, Mahmood Doosti, Hossein Baba Ahmadi Rezaie \\ Department of Clinical Biochemistry, Tehran University of Medical Sciences, Tehran, Iran
}

Received:30 March 2018; Accepted:05 May 2018;

ABSTRACT

Background and Objective: Recent studies have shown that not only the quantity, but also the quality of dietary fatty acids can affect lipid parameters. Elaidic acid is a major hydrogenated by-product of vegetable oil play a role in the development of cardiovascular disease, especially atherosclerosis, through changing lipid profile and increase in inflammation and inflammatory factors. On the other hand, the role of TNF- $\alpha$ is evident in inflammatory pathways and inflammation outcomes, which are involved in the initiation of atherosclerosis. Therefore, in the current study the effect of elaidic acid on TNF- $\alpha$ gene expression, was investigated.

Methods: RAW264.7 cells were treated with 100 and $200 \mu \mathrm{M}$ of elaidic acid for $12 \mathrm{~h}$. Then, expression of TNF- $\alpha$ gene was assessed after RNA extraction and cDNA synthesis.

Result: TNF- $\alpha$ gene expression in RAW264.7 macrophage cell line showed no significant difference for both concentrations compared to the control.

Conclusion: These results indicated that elaidic acid affect the development and acceleration of atherosclerosis in other ways than through TNF- $\alpha$ nuclear receptor.

Keywords: Cell culture, Elaidic acid, Atherosclerosis, Gene expression, Trans fatty acid, TNF- $\alpha$

Corresponding Information: Hossein Montakhab Yeganeh, Department of Clinical Biochemistry, Saculty of medicine, Tehran University of Medical Sciences, Tehran, Iran; E-mail: yegane_email@yahoo.com

Copyright (C) 2018. This is an open-access article distributed under the terms of the Creative Commons Attribution-noncommercial 4.0 International License which permits copy and redistribute the material just in noncommercial usages, provided the original work is properly cited.

\section{Introduction}

Atherosclerosis is a leading cause of death in developed and developing countries, and may soon involve all countries worldwide (1). Atherosclerosis is a progressive inflammatory disease, which begins with gradual deposition of low density lipoprotein cholesterol (LDL-C) in vascular endothelium due to different causes (2). Following these depositions, recruitment of monocytes to endothelial cells and their differentiation into macrophages occur (3).
Due to inflammatory factors, such as cytokines and oxygen free radicals, esterified cholesterolrich macrophages will gradually generate foam cells, which finally results in development of atherosclerosis plaque (4). Therefore, the factors accelerating this process and the way it develops is a matter of the utmost importance in the prevention of development and progression of atherosclerosis (5).

Over the past few decades, numerous studies have shown that not only the quantity, but also the quality of the dietary fatty acids can affect lipid 
parameters, among which the most important ones are HDL-C and LDL-C $(2,6,7)$. As defined, fatty acids through a double bond (MUFA) with cis isomer (CFA) decrease LDL-C to HDL-C ratio and consequently reduce the risk of vascular lesions, especially in heart and brain (8). However, on the other hand, trans fatty acids (TFA) increase the above-mentioned ratio and subsequently the risk of vascular lesions (9). Given that the increase of this ratio is considered as a major risk factor for developing cardiovascular diseases, especially atherosclerosis, it seems necessary to accurately determine the mechanism leading to this outcome (10).

TFA is one of the main saturated byproducts of vegetable oils, which is produced by industrial processes (11). These fatty acids (especially elaidic acid or EA C18:1.9) cause the development and progression of atherosclerosis through change in the lipid profile, exacerbation of inflammation, inflammatory factors, and other major complications (12).

Vascular endothelial cells act as a selective permeable barrier and play a substantial regulatory role in inflammatory processes. Any factors that cause dysfunction in endothelial cells can result in inflammatory complications. Activation of systemic inflammation is a risk factor for coronary heart disease, insulin resistance, diabetes, and heart failure. On the other hand, it is evident that inflammatory cytokines, including IL-6 and TNF- $\alpha$ act as the initiator of inflammatory processes that lead to the development of cardiovascular diseases and atherosclerosis (13). It has been also found that TNF- $\alpha$ induces IL-6 production through activation of adenylate cyclase and/or PKC (14).

In general, since fatty acids are important structural component of adipose tissue, it is very necessary to elucidate the biological effects of various fatty acids on the related genes involved in lipid metabolism and homeostasis. In this regard, it has been proposed that TFA can increase the production of inflammatory cytokines, such as TNF- $\alpha$ and IL-6 (15). As mentioned earlier, TFA, mainly EA, are considered as an important risk factor in most of the diseases, including cardiovascular disease (especially atherosclerosis) due to change in the lipid profile and increase in inflammatory factors (16). Therefore, considering the prominent role that nuclear receptors play in lipid metabolism and homeostasis, any changes in the expression and/ or activity of these receptors cause development of above-mentioned diseases. Therefore, elucidation of the mechanism by which TFA exert their effects, can definitely be helpful in the control of such diseases, since it can offer some practical strategies for the prevention of the diseases and/or their exacerbation.

\section{Materials and methods}

This fundamental-experimental study was conducted in the Department of Medical Biochemistry of Tehran University of Medical Sciences, and the materials used were as follows: Macrophage cell line RAW264.7 (Iran center of genetic resources), cell culture medium, fatal bovine serum (FBS), penicillin/streptomycin antibiotics, and amino acid glutamine (Gibco, USA). RNA extraction Kits or plus mini RNeasy (Cat. No. 74134), cDNA synthesis kit or QuantiTect Reverse Transcription (Cat. No. 205311), TNF- $\alpha$ genes primer, $\beta$-Actin (Qiagene, Germany), and SYBR green real-time PCR (Takara, Japan). as well. The study procedures were as follows:

\section{Culture of macrophage cell line RAW264.7}

Culture of macrophage cell line RAW264.7 was performed in DMEM culture medium containing $10 \%$ FBS, $1.25 \%$ glutamine, and $1 \%$ penicillin/streptomycin antibiotics and the medium was incubated at $37^{\circ} \mathrm{C}$ and $5 \% \mathrm{CO}_{2}$.

Determining the lethal dose (MTT test) 
To determine the lethal dose of EA, MTT test was performed on the cell lines through the following procedures: 20,000 cells were dispensed into each well of 96-well microplates. After preparation of MTT working solution at concentration of $0.5 \mathrm{mg} / \mathrm{ml}$, DMEM medium was replaced by this medium, then the cells were incubated at $37^{\circ} \mathrm{C}$ for $3 \mathrm{~h}$. After passing the mentioned time, the MTT working medium was replaced by dimethyl sulfoxide (DMSO) and was incubated for $15 \mathrm{~min}$ and absorption of each well was measured at $540 \mathrm{~nm}$ using an ELISA Reader.

\section{Conjugation of elaidic acid using bovine serum albumin (BSA)}

EA obtained the required dissolvability to enter the cell after conjugation to BSA, so that EA is dissolved in the minimum amount of $50 \%$ ethanol, and then 0.5 and $1 \mathrm{mM}$ concentrations of EA were prepared by a medium containing $1 \% \mathrm{w} / \mathrm{v}$ fatty acid free albumin. The resultant medium was filtered using a $0.2 \mu \mathrm{m}$ pore size filter and incubated in a shaking incubator at $37^{\circ} \mathrm{C}$ for $2-3$ hours.

\section{Treatment of Cells with EA}

First, the DMEM medium that feeds the cells, was replaced by a new medium containing 0.5 and $1 \mathrm{mM}$ of conjugated EA and cells were incubated for 12 hours at $37^{\circ} \mathrm{C}$.

\section{RNA extraction}

Total RNA of the cells was extracted using a RNA extraction kit (Qiagen) and RNA concentration was determined by measuring its absorbance at $540 \mathrm{~nm}$ using a NanoDrop spectrophotometer. Moreover, the quality of RNA was confirmed by agarose gel electrophoresis.

\section{cDNA synthesis}

The RNA was transcribed into cDNA in a reverse transcription reaction using a reverse transcription kit (Qiagen), according to the manufacturer's instructions.

\section{Evaluating TNF- $\alpha$ gene expression}

According to the instructions of SYBR green kit (Takara Co.) and using a Corbett Rotor-Gene 6000 real-time PCR, TNF- $\alpha$ gene and $\beta$-Actin (as a reference gene), were amplified and the level of gene expression was measured in the control and treatment groups. Finally, the data were analyzed and interpreted by ANOVA statistical test using SPSS software (version 11.5).

\section{Results}

After cell treatment with five different concentrations of EA for 24 hours, the vitability rate of the cells was measured using an ELISA reader device. According to the results of MTT test, it was revealed that toxic and lethal concentration (the concentration that kills 50\% of the cells) was $4 \mathrm{mM}$ and higher.

\section{Results of MTT test}

RAW264.7 cells were treated with 1, 2, 3, 4, and $5 \mathrm{mM}$ of EA for 24 hours, and on and the viability percentage of cells was measured using MTT test and based on the absorption rate using an ELISA Reader machine.

\section{Evaluation of gene expression level}

TNF- $\alpha$ gene expression was assessed using real-time PCR technique. However, after analysis of the obtained results by SPSS software, no significant difference was observed between EA treated and control groups in gene expression. 


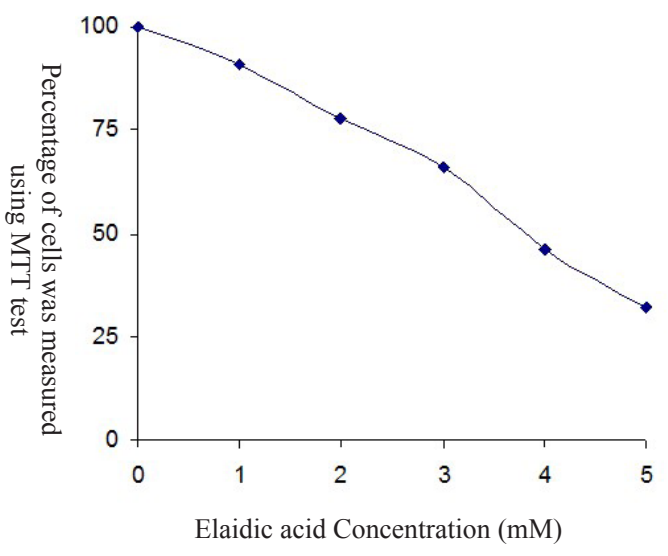

Fig. 1

Results of MTT test. 1, 2, 3, 4, and $5 \mathrm{mM}$ concentrations of elaidic acid (EA) were treated for 24 hours on RAW264.7 cells and the survival percentage of cells was measured using MTT test and based on the absorption rate by ELISA Reader machine.

\section{Discussion}

Cardiovascular diseases are the numberone cause of death in developed countries. Clinical, epidemiological, and laboratory studies have shown a direct relationship between the consumption of trans-fatty acid and development and progression of atherosclerosis (17). However, the subject of attention is the mechanism by

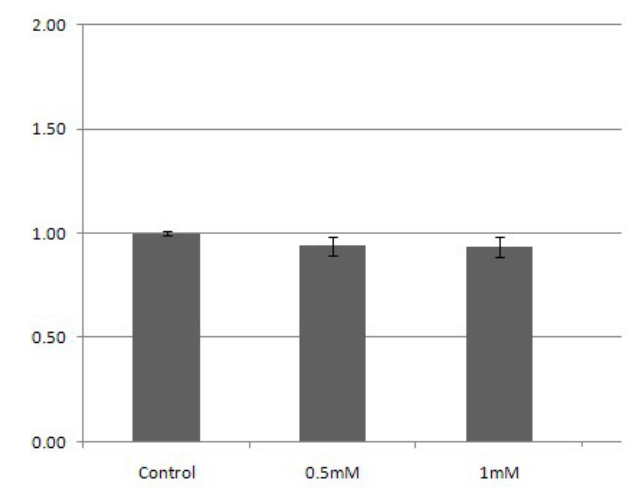

Fig. 2

Elaidic acid Concentration (mM)

The amount of TNF- $\alpha$ gene expression. The obtained RNA from RAW264.7 cells, under 12 hours of treatment with 0.5 and $1 \mathrm{mM}$ concentrations of elaidic acid was duplicated using Real Time PCR technique. At any concentration, there was no significant difference in TNF- $\alpha$ gene expression compared with the control group (the group that was under no treatment with the fatty acid)

which fatty acid affects the development of cardiovascular diseases (18). In this regard, extensive researches have been conducted on inflammation and inflammatory processes as one of the most important initial stimuli in the development of these disorders. Among the inflammatory factors, TNF- $\alpha$ is a well-known and important cytokine, which its involvement in inflammatory reactions has been proved. Accordingly, in the present study, the difference between 0.5 and $1 \mathrm{mM}$ concentrations of EA was evaluated on TNF- $\alpha$ gene expression in RAW264.7 cell line. It was found that EA has no significant effect on TNF- $\alpha$ gene expression at any of the used concentrations, but this result cannot undermine the disadvantages of this fatty acid. Our result is in line with the finding of another study that showed that the consumption of EA has a direct relationship with TNF- $\alpha$ receptor and levels of IL-6 and CRP in women with high body mass index (BMI) (19). Furthermore, nutritional studies have proved that eating high-fat foods accelerates the inflammation by increasing inflammatory cytokines (TNF- $\alpha$, IL-6) and ICAM and causes endothelial activation and consequently inflammation (20). In a research conducted by Bickel (1993), it was indicated that factors, such as mechanical stress, hypoxia, and ischemia can stimulate inflammatory cascades and consequent outcomes through stimulation of different interleukins and TNF- $\alpha$ (21). Hence, considering the mentioned issues and also lack of consensus on TFA mechanism of action, we decided to investigate the effect of EA (the most important TFA) on TNF- $\alpha$ (the most important inflammatory factor) to clarify the mechanism of action of this fatty acid in the development of atherosclerosis. But due to the absence of significant difference in TNF- $\alpha$ gene expression, and on the other hand, considering the results of other relevant studies, other possible mechanisms should be taken into consideration as the final path in the development of cardiovascular diseases. For instance, in an investigation, it was showed that TFA can increase insulin resistance, endothelial damage, and lipid oxidation (22). Accordingly, each of the above-mentioned cases could be 
activated by TNF- $\alpha$ and explain the mechanism of atherosclerosis development. Among other possible mechanisms, TFA incorporation to endothelial cells was proposed by Schepers et al. (23). In addition, in another research, it was found that TFA activate inflammatory processes not by changing TNF- $\alpha$ gene expression, but by changing TNF- $\alpha$ biology through affecting the phospholipids in macrophage cell membrane and signaling pathways (24). On the other hand, in the present study, insufficient duration of treatment $(12 \mathrm{~h})$ may have resulted in no alteration in TNF- $\alpha$ gene expression. Longer treatment period may (48 or $72 \mathrm{~h}$ ), may cause a significant change in the expression of this gene. From the results of this study, it can be concluded that although no relationship was found between TNF- $\alpha$ gene expression and EA and despite certain role of this fatty acid in the development and progression of atherosclerosis, other proposed mechanisms should be investigated.

\section{Conflict of interest}

The authors declare that there is no conflict of interests

\section{References}

1. Mbewu A, Mbanya JC. Cardiovascular Disease. In: Jamison DT, Feachem RG, Makgoba MW, Bos ER, Baingana FK, Hofman KJ, et al., editors. Disease and Mortality in Sub-Saharan Africa. 2nd ed. Washington (DC): World Bank; 2006.

2. Charo IF, Taub R. Anti-inflammatory therapeutics for the treatment of atherosclerosis. Nat Rev Drug Discov 2011;10(5):365-76.

3. Libby P, Ridker PM, Hansson GK; Leducq Transatlantic Network on Atherothrombosis. Inflammation in atherosclerosis: from pathophysiology to practice. J Am Coll Cardiol 2009 1;54(23):2129-38.

4. Rivera MF, Lee JY, Aneja M, Goswami V, Liu L, Velsko IM, et al. Polymicrobial infection with major periodontal pathogens induced periodontal disease and aortic atherosclerosis in hyperlipidemic ApoE(null) mice. PLoS One. 2013;8(2):e57178.

5. Tabaka M. The effects of polyunsaturated fatty acids on coronary disease. JAAPA 2008;21(5):39-40, 42-4.

6. Cox RA, Garcia-Palmieri MR. Cholesterol, Triglycerides, and Associated Lipoproteins. In: Walker HK, Hall WD, Hurst JW, editors. Clinical Methods: The History, Physical, and Laboratory Examinations. 3rd ed. Boston: Butterworths;1990.

7. Schaefer EJ, Gleason JA, Dansinger ML. Dietary fructose and glucose differentially affect lipid and glucose homeostasis. J Nutr 2009;139(6):1257S-62S.

8. Ciccone MM, Cortese F, Gesualdo M, Carbonara S, Zito A, Ricci G, et al. Dietary intake of carotenoids and their antioxidant and anti-inflammatory effects in cardiovascular care. Mediators Inflamm 2013;2013:782137.

9. Sampath H, Ntambi JM. Polyunsaturated fatty acid regulation of genes of lipid metabolism. Annu Rev Nutr 2005;25:317-40.

10. Benatar JR, Gladding P, White HD, Zeng I, Stewart RA. Trans-fatty acids in New Zealand patients with coronary artery disease. Eur J Cardiovasc Prev Rehabil 2011;18(4):615-20.

11. Dhaka V, Gulia N, Ahlawat KS, Khatkar BS. Trans fats-sources, health risks and alternative approach A review. J Food Sci Technol 2011;48(5):534-41.

12. Boden G. Obesity. insulin resistance and free fatty acids. Curr Opin Endocrinol Diabetes Obes 2011;18(2):139-43.

13. Soto-Vaca A, Losso JN, McDonough K, Finley JW. Differential effect of 14 free fatty acids in the expression of inflammation markers on human arterial coronary cells. J Agric Food Chem 2013;61(42):10074-9.

14. Akira S, Hirano T, Taga T, Kishimoto T. Biology of multifunctional cytokines: IL 6 and related molecules (IL 1 and TNF). FASEB J 1990;4(11):2860-7.

15. Barbier O, Torra IP, Duguay Y, Blanquart C, Fruchart JC, Glineur C, et al. Pleiotropic actions of peroxisome proliferator-activated receptors in lipid metabolism and atherosclerosis. Arterioscler Thromb Vasc Biol 2002;22(5):717-26.

16. Upadhyay RK. Emerging risk biomarkers in cardiovascular diseases and disorders. J Lipids 
2015;2015:971453.

17. Siddiqui RA, Harvey KA, Ruzmetov N, Miller SJ, Zaloga GP. n-3 fatty acids prevent whereas trans-fatty acids induce vascular inflammation and sudden cardiac death. Br J Nutr 2009;102(12):1811-9.

18. Siri-Tarino PW, Sun Q, Hu FB, Krauss RM. Saturated fatty acids and risk of coronary heart disease: modulation by replacement nutrients. Curr Atheroscler Rep 2010;12(6):384-90 .

19. Mozaffarian D, Pischon T, Hankinson SE, Rifai N, Joshipura K, Willett WC, et al. Dietary intake of trans fatty acids and systemic inflammation in women. Am J Clin Nutr 2004;79(4):606-12.

20. Peluso I, Raguzzini A, Villano DV, Cesqui E, Toti E, Catasta G, et al. High fat meal increase of IL-17 is prevented by ingestion of fruit juice drink in healthy overweight subjects. Curr Pharm Des 2012;18(1):85-90.

21. Bickel $M$. The role of interleukin- 8 in inflammation and mechanisms of regulation. J Periodontol 1993;64(5 Suppl):456-60.
22. Frohnert BI, Jacobs DR, Jr., Steinberger J, Moran A, Steffen LM, Sinaiko AR. Relation between serum free fatty acids and adiposity, insulin resistance, and cardiovascular risk factors from adolescence to adulthood. Diabetes 2013;62 (9):3163-9.

23. Schepers A, Eefting D, Bonta PI, Grimbergen JM, de Vries MR, van Weel V, et al. Anti-MCP-1 gene therapy inhibits vascular smooth muscle cells proliferation and attenuates vein graft thickening both in vitro and in vivo. Arterioscler Thromb Vasc Biol 2006;26(9):2063-9.

24. Egashira K. Molecular mechanisms mediating inflammation in vascular disease: special reference to monocyte chemoattractant protein-1. Hypertension 2003;41(3 Pt 2):834-41.

\section{How to cite this article}

Yeganeh Montakhab H, Dousti M. Assessment of the Relative Level of TNF- $\alpha$ Gene Expression in RAW264.7 Cells. Mod Med Lab J. 2018;1(1):23-28. 